\title{
Contrabando, redes y poder local en la Guajira de la segunda mitad del siglo XVIII

\author{
Ruth Gutierrez Meza ${ }^{(*)}$
}

Recibido: mayo de 2011

Aprobado: septiembre de 2011

\section{Resumen}

A la luz del Juicio de Residencia del teniente de gobernador Juan de Ortega y Picasso, este artículo analiza como en la provincia de la Guajira (Riohacha) se conectaron el contrabando y el ejercicio de la política local para crear una dinámica donde los diferentes actores sociales intervinieron creando redes donde vinculaban sus intereses y luchas por el contrabando.

\section{Palabras Claves}

Contrabando, poder local, corrupción y redes

\section{Abstract}

In this article will be discussed in the light of Judgement Residence of lieutenant governor Juan de Ortega and Picasso, as in the province of La Guajira (Riohacha) were connected smuggling and the exercise of local politics to create a dynamic where the different actors involved creating social networks linking where their interests and struggles for smuggling.

\section{Key words:}

Contraband, local power, corruption and networks

${ }^{(*)}$ Historiadora de la Universidad de Cartagena y docente de esta institución. Cursa estudios de Maestría en Historia, convenio Universidad Pedagógica y Tecnológica de Colombia-Universidad de Cartagena, categoría B, clasificación Colciencias. Pertenece al grupo de investigaciones Frontera, Sociedad y Cultura del Programa de Historia de la Universidad de Cartagena. Este artículo constituye un adelanto de la investigación que adelanta para su tesis de maestría. regmy@hotmail.com 
E 1 contrabando constituyó uno de los fenómenos característicos de la cultura caribeña durante el siglo XVIII, aun entrados los siglos XIX y XX. En varios de estos territorios este fenómeno continuó siendo un elemento vinculado a las prácticas cotidianas de sus pobladores y relacionado íntimamente con los intereses que se jugaron y disputaron entre los diferentes grupos sociales que convivían al interior de las colonias del Caribe.

Este artículo analiza a la luz del Juicio de Residencia del teniente de gobernador Juan de Ortega y Picasso, como en la provincia de la Guajira (Riohacha) se conectaron el contrabando y el ejercicio de la política local para crear una dinámica donde los diferentes actores sociales intervinieron creando redes donde vinculaban sus intereses y luchas por el contrabando. El Juicio de Residencia consistía en la realización de una investigación que diera cuenta del comportamiento de los funcionarios y las funciones que se les designaba, con un particular interés en el desempeño de aquellos funcionarios que tuviesen injerencia y manejo de caudales. ${ }^{1}$ Los Juicios de Residencia eran conducidos por un juez que para dar cumplimiento a su tarea se trasladaba al domicilio del funcionario, con un secretario y escribano, iniciando su labor con la puesta en conocimiento público de la actividad por realizar, así como el recibimiento de testimonios y quejas ${ }^{2}$.

Esto permite entender como la justicia se convertía en una "justicia colectiva" en la que no sólo participaba el juez residenciador que representaba la autoridad real, sino que la sociedad a través de la denuncia se legitimaba como un organismo de control de significativa importancia en aquellos casos y espacios donde fuese necesario la existencia de otros circuitos que garantizaran la reproducción de cierto "orden" que aunque flexible y mimético permitiera la regulación de la sociedad ${ }^{3}$.

Al finalizar su investigación los jueces elaboraban un documento dirigido a las autoridades competentes donde le informaban el resultado de su labor y donde se le profería una sentencia condenatoria o absolutoria. Cabe señalar que fue poca la eficiencia y la consolidación de los propósitos que esta institución pretendía obtener, y "en no pocas ocasiones era desfigurada de sus fines, pues frecuentemente sirvió como instrumento de venganza o por el contrario como encubrimiento de conductas delictivas" ${ }^{4}$.

Esta institución al igual que otras, intentaba mantener el orden social aceptando la existencia de un cuerpo de "instituciones" que actuaban de forma descentralizada y que se

\footnotetext{
1 Jaime Jaramillo Uribe, "La administración colonial", en Manual de Historia de Colombia, tomo I, Bogotá, Instituto Colombiano de Cultura, 1978, p. 179; José Ots Cadpequi, España en América. Las instituciones coloniales, Bogotá, Universidad Nacional, 1952. pp. 117 y 130.

2 J. Ots C., España en América. Las instituciones coloniales, p. 179.

${ }^{3}$ Diana Luz Ceballos, “Gobernar las Indias. Por una historia ocial de la normalización”, en Historia y Sociedad, No 5, Medellín, Universidad Nacional, 1995, p. 179

4 J. Jaramillo, “La administración colonial”, p. 179
} 
legitimaban a través de la formación de redes sociales de amistad y parentesco a nivel local $^{5}$. Por lo que se puede asumir como un hecho que la justicia se veía adscrita a un cúmulo de intereses reflejados en los testimonios de los denunciantes y en los motivos de sus rivalidades.

El capitán Juan Ortega Picasso tenía una trayectoria en la administración local riohachera; cuando ocupa el cargo de Gobernador de la ciudad de Riohacha ya había ejercido como Juez de Residencia del antiguo Gobernador de la ciudad en dos ocasiones, siendo Teniente General de esa ciudad. Ortega y Picasso inició su carrera militar desempeñándose como Capitán de las compañías de piquetes del refuerzo de la plaza de Cartagena, luego tomó el cargo de Alcalde Ordinario de segundo voto en la ciudad de Tamalameque ${ }^{6}$ y finalmente obtuvo el cargo de Teniente de Gobernador de la ciudad de Riohacha y su jurisdicción, cuyo desempeño fue puesto en entredicho y posteriormente acusado de corrupción. Finalmente, después de ejercer como Gobernador de Riohacha se hizo cargo del batallón de pie fijo de la Plaza de Cartagena ${ }^{7}$.

Cabría resaltar que no fue arbitraria la elección de un militar para que se desempeñara como Teniente de Gobernador de Riohacha y su jurisdicción, teniendo en cuenta la definición que de esta institución colonial da Ots Capdequi, en el sentido de que las capitanías generales y gobernaciones "se crearon en lugares fronterizos con comarcas inexploradas o habitadas por indios rebeldes al yugo de los conquistadores" 8 .

Entonces, utilizando figuras militares en la península de la Guajira, las autoridades reales intentaron controlar estos territorios considerados "salvajes" y a sus habitantes. Sin embargo, José Polo Acuña afirma que esta estrategia de "pacificación" que intentaba crear un plan defensivo que controlara el contrabando en la Guajira, se vio truncada por los intereses de las autoridades locales que encontraban en la práctica contrabandista una lucrativa actividad 9 .

Al terminar su labor como Gobernador de Riohacha y después de realizado el Juicio de Residencia en su contra, Ortega y Picaso regresó a Cartagena donde continuó desempeñándose en tareas militares. En Cartagena vivió en cercanías al convento de Santo Domingo y la iglesia Catedral, lugar a donde fueron remitidos los mensajeros del veredicto que contenía las sanciones económicas que le habían impuesto en la condena de residencia. En la diligencia la situación fue descrita por el escribano de la siguiente manera:

\footnotetext{
5 J. Jaramillo, "La administración colonial”, p. 75

${ }^{6}$ Archivo General de la Nación (Colombia), (AGN), Empleados Públicos, 2, fl. 164r.

${ }^{7}$ AGN, Residencias, 20, fls. 877v. y 18; fl. 528r.

${ }^{8}$ José Ots Capdequi, Estudios de Historia del Derecho Español en Indias, Bogotá, 1940, p. 112.

${ }^{9}$ José Polo Acuña, “Contrabando y pacificación Indígena en la Frontera colombo-venezolana de la Guajira (1750-1800)", en América Latina en la Historia Económica, № 24, México, Asociación Mexicana de Historiadores Económicos, 2005, p. 48.
} 
diligencias $=$ en la ciudad de Cartagena de indias en los días del mes de diciembre de mil setecientos y cincuenta años el subteniente Dn Diego de Llamas que sirve de ayudante de Dragón en el batallón fijo de esta plaza [...] paso en compañía de mi el escribano a esta casa en que hace morada el capitán Dn Juan de Ortega que es alta y notoria en la calle que de las esquinas de la iglesia catedral va al convento de Santo Domingo. ${ }^{10}$

Entre los cargos que se encontraron en el veredicto de la sentencia se halló uno en particular, que le impuso una reconvención económica y tuvo que ver con la denuncia por malos cobros en el Quinto Real que una parte de los rescatadores de perlas riohacheros hicieron ante el Juez y que aparece descrita en los autos de la siguiente manera: "[...] en cuanto a la demanda puesta por Hermenegildo López Sierra, Guillermo Rosado, Jacinto de Amaya, Bernardino de Bermúdez, por sí y por los demás rescatadores de perlas, [...] probado que de todos lo que pasaban al rescate percibía dicho teniente gobernador, una ochava de perla rica" ${ }^{\text {. }}$.

En las piezas de los autos donde se registra la pena que se le atribuyó a Ortega y Picasso se incluyó “[...] restituir a los expresados demandantes y demás rescatadores de perlas a cada uno de ellos tres pesos por cada uno de los rescates que hayan ejecutado [... y por] no haber pagado los reales quintos se condena a dicho teniente Gobernador en pedimento de todo el importe de las ochavas que constase en dicho libro"12.

En la esfera del comercio de perlas este Gobernador no sólo hizo arbitrarios cobros a los rescatadores riohacheros, sino que también participó de este comercio pese a que esta actividad le estaba prohibida por las leyes. Por tal razón en uno de lo fragmentos de las piezas de la "sumaria pesquisa" se le condenó a Ortega a que por haber participado en "[...] el comercio de perlas que consta haber tenido se le multa en seiscientos pesos, aplicados en la forma ordinaria y en todos los costos procesales [...]"13. La última pena económica a la que se vio sometido tuvo que ver con el hecho de que colocó a Nicolás López de Lara ${ }^{14}$ en la cárcel, debido a que este no le había cancelado una deuda pendiente por la venta de unas perlas. En el proceso se describió el caso de la siguiente manera: "por los perjuicios que se le ocasiono con el motivo de la prisión que ejecuto en su persona para el cobro de quinientos y seis pesos que le debía, se le multa en cincuenta pesos" ${ }^{\text {"15 }}$.

Este comerciante de perlas encontró en el juicio de residencia una singular vía que le permitió recobrar todos los beneficios que dejó de obtener durante el gobierno de Ortega y

${ }^{10}$ AGN, Residencias, 18, folio 595r.

${ }^{11}$ AGN, Residencias, 18, fls. 516v.

${ }^{12}$ AGN, Residencias, 18, fls. 517r.

${ }^{13}$ AGN, Residencia, 18, fls. 517v.

${ }^{14}$ Nicolás López de Lara es uno de los testigos del juicio de residencia y comerciante de perlas de la provincia de Riohacha del que más adelante se harán mayores precisiones.

${ }^{15}$ AGN, Residencias, 18, fls. 516r. 
Picasso, quien no lo incluyó entre los miembros que se desempeñaban en la política local. Figurando como uno de los testigos del juicio, Nicolás de Lara ofreció su testimonio como prueba de la corrupción y el mal desempeño que en ciudad de Riohacha había llevado a cabo el Teniente de Gobernador. En este caso, encontramos que la lucha por el poder tomó como instrumento acusador el discurso y la palabra, las cuales llevarían al desprestigio, vergüenza y culpabilidad de Ortega y Picasso. Siendo las palabras y discursos de los testigos las pruebas del juicio, encontramos un principio que, según George Balandier, demuestra que al estar en escena la opinión de un colectivo de individuos contra otro, estas se convierte en ley ${ }^{16}$.

La denuncia de este personaje funcionó aquí como un elemento importante de la imposición del orden en lo que Diana L. Ceballos llama "nivel ascendente", que permitía al testimonio cristalizarse como denuncia ante algunas de las instituciones o aparatos de justicia $^{17}$. Sin embargo, de manera simultánea funcionó como un elemento de retaliación que obedeció a unos intereses particulares, que en este caso eran los del perulero. Es preciso observar como la lucha por el poder convirtió la esfera política en un escenario dramático, donde la trasgresión de las prohibiciones de la sociedad activó la afrenta de los actores sociales que estaban en oposición a los que poseían el poder. Estos actores sociales atacaron con la palabra y el discurso intentando degradar públicamente hasta su punto máximo a los miembros del Cabildo y la municipalidad, con el fin de "salvaguardar" los valores de la sociedad ${ }^{18}$.

En un espacio como la Guajira, Juan Ortega y Picasso se vio enfrentado a las turbulencias e intereses que se generaron de la formación de las redes. La constante lucha por hacer parte del núcleo de individuos que ostentaba el poder local llevaba a aquellos que quedaban por fuera de él a asumir una actitud de vigilancia y fiscalización para hallar las fisuras que les permitieran deshilar esa red e integrarse a ella luego que ésta en busca de su supervivencia iniciara un proceso de mutación. En el Juicio de Residencia también se evaluaron las funciones y el desempeño de los alcaldes ordinarios, de los regidores, los procuradores generales y de todos los que habían obtenido oficios concejiles durante el tiempo que el Capitán Teniente había administrado la provincia de Riohacha.

\footnotetext{
${ }^{16}$ George Balandier, El poder en escenas. De la representación del poder al poder de la representación, Barcelona, Paidós, 1992, p. 45.

${ }^{17}$ D. Ceballos, “Gobernar las Indias. Por una historia social de la normalización”, pp. 184-187.

${ }^{18}$ G. Balandier, El poder en escenas, pp. 23-24.
} 


\section{Un acercamiento a las redes}

Tratando de llevar el análisis sobre el contrabando en el Caribe neogranadino por las vías de una reflexión donde se identifique el papel del actor individual y su desenvolvimiento en el entramado de las redes sociales, donde las relaciones que mantenían unos con otros les permitía construir las dinámicas de su contexto, esbozamos una semblanza de algunos de esos actores sociales ${ }^{19}$.

Lázaro Joseph de Espinal y Herrera, Lázaro Redondo y Luís Joseph Coronel fueron algunos de los alcaldes ordinarios de primer voto que debieron comparecer ante el juez de residencia Don Joseph Nicolás de la Rosa para hacer frente a los testimonios de testigos como Nicolás López de Lara, Joseph Bermúdez, Baltazar Cubelos, el Teniente Andrés de Ávila, Juan Baptista Caballero, el Teniente Guillermo Rosado y Juan Nicolás de Barros. Estos sujetos tuvieron intereses que se reflejaron en el intento por obtener el dominio del poder local mediante las acusaciones de corrupción contra la administración de Juan Ortega y Picasso y sus funcionarios y oficiales. Los testimonios y acusaciones de los testigos tuvieron una funcionalidad adscrita, en teoría, a la "justicia desinteresada" pero connotante de un interés que buscaba como recompensa la obtención de beneficios. Bourdieu explica que "si el desinterés es posible sociológicamente, sólo puede deberse a la coincidencia entre unos habitus predispuestos al desinterés y unos universos en los que el desinterés está recompensado" 20 .

En los autos de la sumaria pesquisa a los tres alcaldes mencionados se les acusaba de no cumplir con obligaciones básicas de su cargo, tales como, "[....] haver dexado de zelar en sus rondas los pueblos amancebados, [no] haciéndolos apartar, casar y castigar en caso de reincidencia, como era de su obligación[....] no haberle puesto su cuidado en que esta ciudad estuviese proveída de bastimentos para la cómoda manutención de los moradores [....] [ y que por la] omisión en la provisión de bastimentos pues por no salir uno de los alcaldes se los llevan los indios guajiros" ${ }^{\prime 2}$.

En estos dos primeros cargos, quedó reflejado que el problema de los alcaldes residía en la omisión que los definía frente a los delitos y desacatos que sucedía ante sus ojos. Es claro que esta omisión no era fortuita, sino que más bien era parte de esa misma dinámica de tratos y negociaciones existentes entre los actores sociales de la provincia (funcionarios/vecinos; funcionarios/indios guajiros; vecinos/indios guajiros). A partir de esto, puede observarse la existencia de una red social con intereses económicos alrededor del comercio de ganado y bastimentos que abastecían la ciudad.

${ }^{19}$ Bertrand Michel, "Redes sociales, poder e identidad en las sociedades latinoamericanas (siglos XVI$\mathrm{XX}$ )", en Bertrand Michel (coord.), Configuraciones y redes de poder. Un análisis de las relaciones sociales en América Latina, Caracas, Tropykos, 2002.

${ }^{20}$ Pierre Bourdieu, Razones prácticas sobre la teoría de la acción, Barcelona, Anagrama, 1997, p. 155.

${ }^{21}$ AGN, Residencias, 17, fls. 355v, 375r y 381r. 
El estado de escasez de alimentos en la ciudad por parte de los alcaldes que permitían que fuesen los guajiros quienes los trajesen, es una muestra de cómo entraba la "ilegalidad" en el comercio que abastecía la provincia, y de cómo se filtraba a través de la esfera de la corrupción y los intereses individuales de quienes ostentaban los cargos públicos y demás oficios concejiles.

En esta dinámica se puede evidenciar "la reciprocidad" entre los actores sociales que convivían en la península. Si los funcionarios no realizaban las obligatorias rondas nocturnas para vigilar los comportamientos de los habitantes, sería más fácil la práctica de actividades como el contrabando calificadas por la norma como delito, pero del que amplios segmentos de la población se beneficiaba e intentaba mantener como elemento integrador de sus prácticas cotidianas.

La corrupción entre los funcionarios hispano/criollos denunciada por los testigos, no se limitó a contravenir solamente las normas de castigo, vigilancia y abastecimiento de la ciudad, sino que también halló la manera de encubrir los delitos en los registros y en la documentación reglamentaría que debían llevar durante su mandato, además de no cumplir con la frecuencia de las reuniones del cabildo. Así se aparece la denuncia en el fragmento de uno de los autos del juicio:

[....] Hacercele cargo de no haber puesto su cuydado en que el libro capitular del dicho año, se huviese encuadernado según el orden pues pliego a pliego; como se halla, tiene fácil desunión, del mismo modo ha faltado a hacer cavildo cada semana como era obligación para tratar las cosas del bien común, pues en todo el dicho año solo se hicieron seis juntas capitulares a excepción de la de elecciones.

Hacérsele cargo de haber tenido descuido en que el protocolo de escrituras se formase de manos enteras y no pliego a pliego, como esta encuadernado contra el orden y facil desunión de ellos y del mismo modo no haver puesto en las escrituras que otorgo la rason de los derechos que llebo por ellas como era de su obligación faltándole también a este registro la certificación final con que debe serrarse, pues solo tiene una nota simple, como una rubrica con nombre $[\ldots . .]^{22}$

Que los libros capitulares y los protocolos de escrituras no fueran encuadernados de la manera como se ordenaba abría la posibilidad de que las hojas que los conformaban al estar desunidas pudiesen "desaparecer", "perderse" u omitirse bajo la excusa de un "extravío". Esta acción atentaba contra el registro y la veracidad de la información que llegaba hasta las autoridades superiores y representaba un elemento significativo para que el juez residenciador tuviera en cuenta a la hora de dictar su sentencia

Sin embargo, en la provincia de Riohacha esta infracción se había convertido en una particularidad tradicional para los funcionarios hispanos criollos, lo que les permitió a los alcaldes ordinarios tener un "punto a favor" de su defensa, y así lo manifestaron algunos de ellos en los informes:

${ }^{22}$ AGN, Residencias, 17, fls. 356r, 356v, 361r, 362v, 375v y 381v. 
... [respondiendo al cargo que se me hace sobre] la enquadernación opuesta de el libro capitular, a la que legalmente se debe practicar. Pero como en esta ciudad ha sido eso costumbre el enquadernamiento en esa manera, por carecer de disposición a que nos pudiéramos arreglar, [ilegible] o alguna que se pudiera haber expedido en las veces pasadas, me juzgo inculpable como del mismo modo me indemnizo de la culpa correspondiente al defecto del cargo de semaneros que conducen a las materias del bien publico mediante a que, como en esta ciudad no se encuentran las noticias para la formación de aquellos, a mas de que rara vez se pueden juntar los individuos de el ayuntamiento verse retirados en las asistencias en sus haciendillas porque como oficiales al ningún sueldo, ni conocimiento les urge su personal trabajo para pasar la vida, con sus mujeres y familia, y solamente a presión de caso importante, se hace convocación ${ }^{23}$.

El discurso en el proceso de defensa de los acusados arroja luces sobre la forma como se asumían en la cotidianidad y en el plano de la realidad de una zona de frontera, las disposiciones y protocolos organizados por las autoridades hispanas. Es aquí donde la ecuación del espacio/tiempo propuesta por Diana L. Ceballos materializa su efecto y demuestra como el Caribe y para nuestro caso la Guajira, es un caso particular donde el "orden" establecido por el poder central se flexibiliza para acomodarse al espacio y a las practicas de cada territorio. ${ }^{24}$

Las prácticas sociales que se llevaban a cabo al interior de este grupo de individuos se podrían definir con los parámetros de Bourdieu, quien las considera como "aptitudes que se adoptan para moverse, actuar y orientarse según la posición ocupada en el espacio social, según la lógica del campo y de la situación en la cual se está comprometido" 25 . Las prácticas de los hispano criollos funcionaron bajo la lógica del campo contrabandista en que se desenvolvían y bajo sus urgencias y ritmos, más no precisamente en obediencia a la regla.

Bourdieu se plantea un interrogante que lo lleva a interesarse por saber hasta que punto y en qué proporción los miembros de una sociedad determinada respetan la norma. ${ }^{26}$ Entra así a considerar como las prácticas, asimiladas a través de la práctica, por un grupo social impulsan a actuar en relación a un espacio objetivamente constituido como estructura de exigencias, como las "cosas a hacer", ante una situación determinada. Termina concluyendo que "las coerciones y las exigencias del juego (en este caso del contrabando), por más que no estén encerradas en un código de reglas, se imponen a aquellos- y a aquellos solamente- que, porque tienen el sentido del juego, es decir el sentido de la necesidad inmanente del juego, están preparados para percibirlas y cumplirlas"27.

\footnotetext{
${ }^{23}$ AGN, Residencias, 17, fls 358v, 359r.

${ }^{24}$ D. Ceballos, “Gobernar las Indias. Por una historia social de la normalización”, pp. 49-170.

${ }^{25}$ Alicia Gutiérrez, Las practicas sociales: Una introducción a Pierre Bordieau, Madrid, Tierradenadie, 2002, p. 73.

${ }^{26}$ Pierre Bourdieu, El sentido práctico, Madrid, Taurus, 1991, p. 68.

${ }^{27}$ P. Bourdieu, El sentido práctico, p. 75.
} 
Las decenas de quejas e informes que se enviaban a los virreyes acerca de las situaciones que se presentaban en un espacio fronterizo como este eran copiosas, sin embargo, los cambios que las quejas lograron no representaban una equivalencia frente a esa corrupción en el ejercicio de la política local y modo de vida "ilegal" que llevaban los funcionarios públicos que allí residían.

Las reuniones del cabildo eran de suma importancia y tener un tipo de acusación como la de no llevarlas a cabo implicaba la existencia de un descuido gubernamental de los pueblos y las villas, pues era el cabildo el centro de toda actividad política local y la única forma de gobierno en los mundos de los pueblos y las villas ${ }^{28}$.

En estas condiciones podía ponerse en duda si realmente los alcaldes ordinarios y los miembros del cabildo estaban llevando un gobierno organizado o si su intención era la vehemente participación en el juego contrabandista, sin embargo, las condiciones, al parecer, estaban dadas para absolverse de este cargo, pues si los sueldos de los funcionarios no eran suficientes para su manutención ellos debían dedicarse a sobrevivir, y en este territorio se "sobrevivía" participando de las actividades y negocios que se surgían del ejercicio del contrabando.

Los alcaldes ordinarios Lázaro Joseph de Espinal, Lázaro Redondo y Luís Joseph Coronel se vieron compelidos a enfrentar un ultimo tipo de cargo, que en este caso tenía que ver con la implicación que habían tenido en la elección de algunos miembros del cabildo cuyos nombres estaban prohibidos en el cuadro de los candidatos por ordenes del virrey. En el juicio de residencia se nombraron los cargos en los siguientes términos: "[...]Hacérsele cargo de haver dado voto en las elecciones de primero de Enero del año cuarenta y cuatro, para que fuesen regidores Don Pedro Theran Freile, y Don Silvestre de Peralta estando prohibidos estos nombramientos por la ley 4 Libro 8 tit. 2 de la recopilación en que se mando que no se provean los regimientos por elección o suerte o otra forma ..."29.

En defensa suya, los alcaldes ordinarios arguyeron que no podían ser afectados por algo que ya era una costumbre en las elecciones de los cabildos municipales de esta ciudad, pues los nombres de estos regidores habían aparecido con frecuencia durante varias elecciones y sus personalidades habían sido estudiadas anteriormente, de manera que el hecho de que ellos los nombraran no debía ser un delito, ya que además no conocían la orden del virrey de que ellos estaban prohibidos para el cabildo. Respondiendo en defensa suya los alcaldes ordinarios arguyeron en los registros de las pesquisas lo siguiente:

Resulta así mismo del sexto cargo, la culpa de votar para regidores vocales en los sujetos que se expresan por oponerse a ello, la ley real donde, recopilaron, la qual no me obra ni perjudica, por cuanto ha sido costumbre

\footnotetext{
${ }^{28}$ Margarita Garrido, Reclamos y representaciones. Variaciones sobre la politica en el Nueva Reino de Granada. 1770-1815, Bogotá, Banco de la República, 1993, pp. 117-121.

${ }^{29}$ AGN, Residencias, 17, fls. 356v.
} 
antiquísima en esta republica la [elección]. a tales regidores desde que renunciaron estos oficios, los quales tenían en propiedad o bien porque aquellos primeros institutores les pareció acertado por algún recto concejo, o superior exposición o por la inteligencia de algún jurisconsulto y... dan lugar a estas elecciones, lo qual ha permanecido hasta que el excelentísimo don virrey de este nuevo reino lo prohibió como hoy se experimenta ${ }^{30}$.

Bajo estas condiciones, los alcaldes ordinarios establecían los parámetros que se debían utilizar para enjuiciarlos, dadas las particularidades de las dinámicas del poder político en Rio de la Hacha, sin embargo, en este Juicio de Residencia encontramos como el entramado de las redes sociales les permitirá a los alcaldes salir bien librados.

Las acusaciones de Guillermo Rosado, Juan Nicolás de Barros, Joseph Bermúdez, Baltazar Cubelos, el Teniente Andrés de Ávila y los demás testigos, se enfrentaban a unos lazos de clientelismo y negociaciones "ilegales" de las que ni siquiera ellos escapaban, pues en el negocio perulero algunos de estos testigos también tenían participación. Esto es una clara reafirmación de que éste espacio era una frontera móvil y porosa donde los actores sociales se movían entre una esfera y otra, y un negocio y otro $^{31}$.

Para el caso de Guillermo Rosado, por ejemplo, encontramos que en el momento del juicio de Residencia hacia parte de los llamados rescatadores de perlas, encargados de comprar las perlas a los indios guajiros para luego traerlas a la ciudad. Rosado denuncia a Ortega y Picasso no sólo por intervenir, sino también por la "corrupción" con la que administraba las entradas de las cajas reales, en este caso, la entrada de los quintos que se cobraban sobre las perlas. Esto se deduce de los siguientes autos donde se registraron las demandas de los testigos y algunos otros comerciantes: “... en cuanto a la demanda [de no haver pagado los reales quintos] puesta por Hermenegildo López Sierra, Guillermo Rosado, Jacinto de Amaya, Bernardino de Bermúdez, por sí y por los demás rescatadores de perlas ...".32

Hacia el año de 1753, seis años después de haberse realizado el juicio, Guillermo Rosado se desempeñó como capitán de una compañía de pardos que debía impedir la entrada de balandras extranjeras. Sin embargo, por supuestas complicaciones de salud fue removido de su cargo, dejando en su lugar a Basilio de Amaya, un integrante de una de las familias dedicadas tanto al taladrado de Perlas como al contrabando de ellas en la ciudad de Riohacha. El auto que contiene esta explicación describe el suceso en los siguientes términos: "y aunque el... dicha compañía de pardos Gui[ller]mo Rosado; es hombre de

\footnotetext{
${ }^{30}$ AGN, Residencias, 17, fls. 359r.

${ }^{31}$ AGN, Residencias, 21, fls. 813r. y 813v. Para el caso de Guillermo Rosado y Joseph Bermúdez, por ejemplo, encontramos que son rescatadotes de perlas que denunciaron a Juan Ortega y Picasso por cobrarles el quinto sobre las perlas y no pagarlo a las cajas reales.

${ }^{32}$ AGN, Residencia, 18, fl. 516v.
} 
empeño y conducta me parecía [...]tado se reformase por el con[cepto] de aogo que padece y ocupase su [...]peo el alférez de dicha compañía Basilio de Amaia”,33.

Años después Guillermo Rosado es colocado en otro cargo de tipo militar tal como lo señala Francisco Piñero, comandante del batallón de a pie de la ciudad de Cartagena en 1761, quien en un auto responde a unas acusaciones establecidas por el "cabo principal de conquista Bernardo Ruiz, ${ }^{34}$ quien designó a Rosado como capitán: "habiéndole su Exa., concedido nombrar quatro capitanes y los subalternos correspondientes y en caso que fuese necesario nombrase dos mas, como lo hizo y consta de la lista que me remitió y oí a su Exa., como ha nombrado ahora a Francisco Lopez, Juan Manuel de Luque, Diego Lopez, Sebastián Suarez, Jph. Martín Bermúdez, Juan de Estrada, Lorenzo Estrada, Guillermo Rosado y otros, [...]"

A partir de lo anterior puede verse una particularidad de las dinámicas y luchas por el poder, el dominio de la política local y el contrabando. El nombramiento de los capitanes por parte de Bernardo Ruiz aclara un hecho importante, y es el de que estos individuos, o por lo menos algunos de ellos estaban relacionados con el trato "ilegal" y/o con el cacique Cecilio López al igual que el conquistador que los nombraba ${ }^{36}$.

Francisco López, como lo veremos mas adelante fue uno de los regidores nombrados por Ortega y también es el hijo de Cecilio López, el "cacique mayor". Joseph M. Bermúdez apareció como uno de los testigos que acusaron a Ortega y a quienes obtuvieron oficios concejiles durante su gobierno considerado de corruptos y contrabandistas. No obstante, trabajará ahora junto a uno de ellos (Francisco López) y nombrado por un miembro de la red de los que negocian con los López Sierra ${ }^{37}$.

En cuanto a Rosado podría decirse que su colocación en el cargo de Capitán obedecía a intereses particulares de carácter comercial entre estos dos actores, lo que muestra además otra faceta donde Guillermo Rosado se desenvolvía fácilmente, el contrabando. En un informe que Francisco Piñero envía al virrey en su defensa por los cargos que Ruiz de Noriega le levantó explicaba que: "ahora pues los ganados que ha sacado para Jamaica son

33 Josefina Moreno y Tarazona, Materiales para el estudio de las relaciones inter-étnicas en la Guajira, siglo XVIII, (Documentos y Mapas), Caracas, Biblioteca de la Academia Nacional de Historia, 1984, p. 49.

${ }^{34}$ J. Polo, “contrabando y Pacificación”, 108-111. "En 1760 la Corona española contrató al asentista de negocios y víveres Bernardo Ruiz de Noriega, para erradicar el trato ilícito que se presentaba a lo largo de la costa. Además debía "pacificar" y someter a los indios guajiros, para cuyo efecto le concedió el titulo de pacificador [...]. Al llegar a la Guajira, Ruiz entabló negociaciones con el cacique mayor Cecilio López Sierra en el pueblo de Boronata, fue padrino de oleos de una hija suya".

${ }^{35}$ AGN, Miscelánea, 52, fls. 1-68. J. Moreno, Materiales para el estudio de las relaciones inter-étnicas en la Guajira, p. 107.

${ }^{36}$ José Polo Acuña, "Una mediación fallida: las acciones del cacique Cecilio López Sierra y el conflicto hispano-Wayúu en la Guajira, 1750-1770", en Historia Caribe $\mathrm{N}^{\circ}$ 4, Barranquilla, Universidad del Atlántico, 1999, pp. 66-77.

${ }^{37}$ AGN, Miscelánea, 52, fls. 1-68. J. Moreno, Materiales para el Estudio de las Relaciones Inter-étnicas en la Guajira, Siglo XVIII, p. 107 
comprados con dinero al pronto y resto en devito al Capitán D. Hermenegildo de Sierra, Guillermo Rosado, y otros vecinos..."38.

Francisco Piñero denunciaba a los miembros de la red de Bernardo Ruiz como activos contrabandistas de ganado. Utilizando la denuncia intentaba luchar por el dominio del poder local y los beneficios que este traía de manera inherente. Entre los testigos acusadores encontramos a J. Baltasar Cúbelos, un individuo que participó como testigo en la denuncia que Juan Ortega y Picasso le hizo al alguacil mayor Don Andrés del Posso en la ciudad de Tamalameque en el año de 1745. Balthasar Cubelos, al igual que Fernando de la Rossa, aparecen en las piezas de los autos de la demanda contra Andrés del Posso como testigos que reafirmaron la serie de "abusos" y "corrupciones" de este alguacil. Ante la ausencia del escribano que registrara los acontecimientos, Ortega y Picasso firmó la diligencia anotando la importancia de los testigos para la veracidad del informe. No obstante, Joseph Baltasar apareció en el año de 1747 como un testigo acusador del gobierno de Juan de Ortega.

Vemos entonces que este juicio de residencia permite develar las dinámicas de las redes sociales y la forma como cada actor social intervenía en el contrabando a través del dominio de los espacios y del ejercicio de la política local. De manera que más que afirmar la existencia clara y evidente del contrabando, observamos concretamente como interaccionaron los miembros del cabildo y la municipalidad que ejercieron su cargo durante el gobierno de Juan de Ortega y Picasso y las prácticas socioculturales que ejercieron, entre ellas el contrabando.

Para el caso de los regidores tenemos a Pedro Fuentes, Francisco de Sierra, Manuel Redondo y Silvestre de Peralta. Entre ellos encontramos la presencia de un mestizo de Boronata que venía de la parentela del "cacique mayor de la nación Guajira", Cecilio López Sierra, era Francisco López no solo hijo del cacique sino que además era sobrino del capitán de la parcialidad de Chimare, uno de los indígenas que ofreció mayor resistencia a la pacificación hispana ${ }^{39}$. Francisco de Sierra con frecuencia se desenvolvió en la política local de la provincia de Riohacha, también en las campañas de "pacificación" y reducción de los nativos de la península, funciones que utilizó en su provecho todas las veces que pudo ${ }^{40}$.

Algunos de los cargos que se les atribuyeron a los anteriores procuradores generales eran similares a los que se le levantaron a los alcaldes, otros diferían un poco. Entre los autos donde aparecen los cargos encontramos la siguiente información: "Hacérsele cargo de no haver procurado como tal regidor que se hiciesen casas de cavildo, cárcel y... cuyas obras,

${ }^{38}$ J. Polo, "Una mediación fallida: las acciones del cacique Cecilio López Sierra y el conflicto hispanoWayúu en la Guajira, 1750-1770".

${ }^{39}$ AGN, Historia Civil, 20, fls. 516v.

${ }^{40}$ AGN, Milicias y Marina, 124, fls. 864v. a 866v. En su testamento Cecilio López solicitó que Francisco, su hijo, fuese nombrado como su sucesor en el cargo de Cacique Mayor de la Nación Guajira en 1773 .

El Taller de la Historia, vol. III, No 3, 2011, pág. 223-240. Issn: 1657-3633

Programa de Historia, Facultad de Ciencias Humanas, Universidad de Cartagena de Indias, Colombia 
como públicas son el mayor lustre de la ciudad. Compruevase este cargo con las deposiciones de Joseph Bermúdez que en la décima quinta pregunta al folio octavo se remite a la undécima buelta del folio séptimo donde dice que no hay en la ciudad estas obras publicas ...."41.

Las obras públicas, es decir, la construcción de cárceles, carreteras, puentes y mantenimiento de la plaza central de la ciudad, entre otras, era una de las obligaciones prioritarias de los cabildos municipales ${ }^{42}$. Frente a la ausencia de las obras públicas, los testigos presentaron ante José Nicolás de la Rosa una acusación que al parecer no tendría modo de hallar un descargo, ya que ante la vista de todos la ciudad se hallaba desprovista de las obras que con los ingresos de las cajas reales se debieron llevar a cabo durante el tiempo que los regidores habían desempeñado su cargo.

Parecía que no habían excusas ni vías de defensa para los regidores, pues al anterior cargo se les sumó el hecho de “... no haber tenido caja contable, ni sin ella en que guarde[n] el archivo, libros y privilegios de la ciudad..."43. Lo que significaba que durante el ejercicio de sus funciones no habían llevado de manera sistemática los registros que tuvieran los movimientos de los ingresos de las cajas reales, pero tampoco se veía en la ciudad la inversión, lo que dejaba demostrado la patente corrupción entre los funcionarios.

Evidentemente se vieron acusados de ocultar -ya fuese por omisión inculpusa o deliberadala información o evidencia que podía aclarar este problema. Si no se llevaban registros ni caja contable no había entonces fuentes concretas que permitieran averiguar por los usos y destinos de los ingresos municipales. Silvestre de Peralta, por ejemplo, se defendía ante el residenciador arguyendo que las rentas que entraban a las cajas reales eran muy bajas como para intentar llevar a cabo obras públicas en la ciudad ${ }^{44}$. Por su parte, Francisco López pedía ser absuelto de dicho cargo bajo el argumento de la ausencia de fondos de las cajas reales debido a que estos provenían de la matanza de ganados, lo cual se daba pocas veces y por consiguiente, pocos eran los ingresos. De esta manera, invitaba a los acusadores a recordar las circunstancias en que se daban los delitos y que además no olvidaran que las rentas que los regidores devengaban como sueldos eran mínimas ${ }^{45}$.

Finalmente nos encontramos con los procuradores generales, entre quienes figuran Hermenegildo López Sierra y Pedro Yanzi. En este cuadro tenemos nuevamente la presencia de un mestizo de la parentela del cacique Cecilio López, que nos permite ver como los parentescos funcionaban como un hilador a partir del cual se entretejían las redes del poder local. El capitán Hermenegildo López, como se explicará más adelante, tuvo un significativo lugar en la red social de la ciudad de Riohacha gracias a que sus lazos

\footnotetext{
${ }^{41}$ AGN, Residencias, 17, fl. 366v.

${ }^{42}$ M. Garrido, Reclamos y representaciones, p. 121.

${ }^{43}$ AGN, Residencias, 17, fls. 366r.

${ }^{44}$ AGN, Residencias, 17, fls. 395r.

${ }^{45}$ AGN, Residencias, 17, fls. 369r. y 369v.
} 
familiares con el cacique mayor, un personaje de gran influencia en los negocios de contrabando y en la esfera social y política, le garantizaba un espacio en la red que dominaba el poder local y el acceso a los beneficios del contrabando.

Es claro que los intereses individuales debían colectivizarse para que funcionaran con efectividad, pues en la esfera del contrabando convergían variables a tal punto de que no era suficiente con tener los géneros, había que dominar las rutas por las que se contrabandeaban y tener el contacto con aquellos que vivieran cerca de ellas o los encargados de vigilarlas. Era de esta forma como la práctica del contrabando podía llevarse a cabo, es decir, con la apuesta en común de hispano criollos (vecinos/ autoridades), mestizos e indígenas para unirse en una red donde todos colaboraban pero a la vez cada uno buscaba sus propios intereses y se beneficiaba del otro para obtenerlos.

En el caso de Hermenegildo López encontramos que por largo tiempo había sido un Comandante de Milicias indígena, acogido por las autoridades hispanas para la tarea de ayudar a la reducción de los nativos guajiros y a vigilar el camino de la boca de Calancala, sin embargo, ahora se veía comprometido en un juicio de residencia acusado de corrupción. Cabría entonces preguntarse y averiguar hasta que punto el estar involucrado en una red política clientelista le permitiría salir bien librado del juicio ${ }^{46}$.

Al final nos daremos cuenta que uno de los puntos importantes para los integrantes de la red es saber desenvolverse al interior de ella y saber que cuando esta muta hay que cambiar junto con ella y adaptarse a la nueva forma y a los nuevos integrantes que esta toma. Hermenegildo López permanecerá en cargos públicos y militares con el paso de los años gracias a que descubre las estrategias para mantenerse incluido en la red política local riohachera $^{47}$.

Los procuradores generales tenían a cuestas los siguientes cargos:

Primeramente se le hace cargo de haver dexado de zelar en sus rondas los pueblos amancebados, haciéndolos apartar, casar y castigar en cargo de reincidencia, como era de su obligación

Hacérsele cargo de haver faltado a pedir a los alcaldes ordinarios y demás ministros del cavildo que procurasen, y solicitasen tener la republica abastecida y proveída de mantenimiento lo que era obligado hazer en fuerza de su oficio y de este ha resultado carecerse de los víveres necesarios ${ }^{48}$.

Estos cargos envolvían una despreocupación que al mismo tiempo implicaba la existencia de tratos comerciales "ilegales", pues si los procuradores no se esmeraban en mantener

\footnotetext{
${ }^{46}$ AGN, Miscelánea, 162, fls. 694-697. J. Moreno, Materiales para el estudio de las relaciones interétnicas en la Guajira, Siglo XVIII, p. 115

${ }^{47}$ Ibid.

${ }^{48}$ AGN, Residencias, 17, fls. 371, 372v, 397v. y 98r.
} 
proveídas las ciudades, alguien si debía hacerlo y en esta provincia los guajiros estaban dispuestos. La conexión entre los miembros del cabildo y los jefes de parcialidades, debió ser patente, de la misma manera que lo debió ser el comercio "ilegal" de provisión para la provincia. Los indios de las parcialidades -sobre todo los del norte de la provincia- tenían acceso a una diversidad de géneros gracias al contrabando que se realizaba con los extranjeros en los puertos de la alta Guajira ${ }^{49}$.

Los procuradores generales exponen un cuadro de situaciones "criticas" de la provincia en su defensa. Argumentaban ante el Juez José Nicolás de la Rosa el hecho de que los funcionarios públicos contaban con un sueldo tan mínimo que no les permitía ejercer sus cargos de tiempo completo en la ciudad. Por tal razón debían retirarse a sus estancias ubicadas en los pueblos de la península para residir y mantener a sus familias, al punto de que la asistencia a cabildos semaneros para "tratar las cosas del bien común" no se les hacía fácil, en consecuencia, sólo se reunían para casos estrictamente necesarios. Hermenegildo López, por ejemplo, anotó en la pieza del auto de su defensa lo siguiente:

... Lo primero que este ayuntamiento siempre se ha compuesto de personas anuales sin sueldo, ni renta con que poder mantenerse de asiento en esta ciudad y sus casas para que con esta asistencias se pudieran celebrar los semaneros, para reparar las cosas del bien publico, y la... quando ha sido materia presisa, como el deber por el libro capitular de dicho año además que faltando motivos suficientes, sobre que fundar aquellas, me parece necesario, por lo que este mal formado cargo no me perjudica por las razones, enunciadas; lo otro que el testigo... pudiera tener presente que al pedir fomentar abastos en una ciudad necesita el que haya y resida en ella aquel caudal o señalada providencia de donde se saque o gaste lo que pareciese a otros usar para aquello, y que esta solo tiene el de los propios, los que como tan sumamente cortos se convienen en las festividades... y desagravio con sabiduría de todo el ayuntamiento según costumbre antiguada y como quieran que faltan las cosas de donde ellos presenten son de tan poco momento que no equivalen a las pensiones de la ciudad; sin embargo, de que el predicho año se repartieron boletas, al vecindarios señalándole a cada uno el numero de veces que debía pasar para el abasto de carne en esta ciudad por lo que no me comprende dicho cargo y en cuyos términos ... ${ }^{50}$.

Con este discurso apelan nuevamente, al igual que los alcaldes, a los pocos ingresos que se obtienen de las cajas reales para el mantenimiento de la ciudad y el pago de los salarios de los funcionarios públicos. Sin embargo, y pese a que ser un funcionario publico, aparentemente era un sacrificio, este juicio de residencia no es más que la muestra de la lucha por hacerse de un espacio en la esfera de la política local.

\footnotetext{
49 Antonio Narváez y de la Torre, "Informe sobre la provincia de Santa Marta y Río Hacha de 1778”, en Sergio Elías Ortiz (comp.), Dos economistas coloniales, Bogotá, Banco de la República, 1954.

${ }^{50}$ AGN, Residencias, 17, fls 374v. y 374r.
} 
De alguna manera era cierto que los sueldos de los empleados municipales eran sumamente bajos y casi inexistentes ¿pero por que la elite y los comerciantes riohacheros buscaban hacer parte de un gobierno que "legalmente" no les pagaba? Es ahí donde reside el entramado de este asunto y es donde precisamente se descubren los intereses que llevaban a las autoridades y a la municipalidad a inscribirse en una práctica que connota ganancias y beneficios pero que al mismo tiempo exige capacidades y espacios geográficos y políticos para su puesta en escena, además del desarrollo de relaciones clientelistas que la respalden.

Guillermo Rosado, Nicolás de Barros, Nicolás de Lara, Joseph Bermúdez, Baltasar Cubelos y el teniente Andrés de Ávila, tenían vivos intereses en el contrabando, esto se evidencia en el hecho de que no sólo eran negociantes de perlas, sino que además tenían hatos y haciendas en las inmediaciones de los pueblos cercanos a Riohacha. Guillermo Rosado tenía hatos en Laguna Salada, Marbella y en el pueblo de La Cruz ${ }^{51}$. Al quedar por fuera de la red que dominaba la política local y cuya cabeza en este caso era el teniente Picasso, las dificultades para beneficiarse del contrabando de ganado o de cualquier otro tipo de género se acrecentaban. Es esto lo que le da valía a las denuncias de estos individuos que lucharán a toda costa por sus intereses ${ }^{52}$.

Teniendo conocimiento de los beneficios que obtendrían si lograban entrar en la red social de clientelismo y corrupción de la política local en la provincia lo que debían conseguir era el desplazamiento del otro campo de poder, tal como se observa en el juicio de residencia de Juan Ortega y Picasso. Con el dictamen de José Nicolás de la Rosa la red tendría que mutar de acuerdo a los resultados que se obtuviesen, es decir, si era necesario darle la espalda al mismo que los había incluido en la red para apegarse a las futuras cabezas de este, todo sería justificado y resarcido en aras de alcanzar los intereses propios.

El 17 de Noviembre de mil setecientos cuarenta y seis Joseph Nicolás de la Rosa terminó de recibir los informes de los cargos y descargos que contra alcaldes, regidores, procuradores y demás funcionarios que obtuvieron oficios concejiles durante el tiempo que gobernó Juan de Ortega. Después de analizados los autos en octubre de 1749, el fallo del juez fue el siguiente

... fallamos atento a los autos y meritos del prozeso a que nos remitimos que por las culpas que de ello resultan contra dicho teniente que fue, Don Juan De Ortega le devemos condenar en la forma siguiente $=$ En quanto al segundo cargo que resulta justificado de haver permitido el desembarco de las harinas de la balandra Francesa en veinte mill setecientos cuarenta y siete se le

\footnotetext{
${ }^{51}$ AGN, Miscelánea, 122, fls. 603-613. J. Moreno, Materiales para el estudio de las relaciones interétnicas en la Guajira, pp. 146-147.

${ }^{52}$ AGN, Residencias, 17, fls. 354v-462r.
} 
condena a dicho teniente de gobernador en prision perpetua de todo oficio de justicia en estos reinos, y en quatro cientos pesos de multa... ${ }^{53}$.

Contra Juan de Ortega también pesaron las acusaciones de los rescatadores de perlas, incluyendo las de Hermenegildo López, uno de los procuradores generales que obtuvo su cargo bajo el mandato de Juan de Ortega. La red ya daba sus primeros síntomas de mutación, no obstante el resto dependía del nivel de conexiones que cada acusado tuviera para lograr ser absuelto.

A través del juicio de residencia encontramos que los resultados fueron lo esperado para los acusados; el juez de residencia declaró como buenos ministros a todos los funcionarios sobre los que pesaban las acusaciones, y absolvió a Juan de Ortega de algunos de sus cargos como aparece registrado en la diligencia del dictamen del juez en el siguiente párrafo: “... En los demás cargos se le absuelve y declara por buen ministro y lo mismo a Don Francisco de Sierra regidor y a Don Hermenegildo López Procurador general de aquel año, e igualmente, a Don Thomas de Ibarra, y en quanto a los ministros del año de setecientos y cuarenta y quatro a Don Luís Coronel alcalde ordinario [también] declaración y absolución se entienda para los demás ministros..."

\section{Conclusión}

En conclusión, puede decirse que los Juicios de Residencia como fuente documental útil para el historiador permiten estudiar la sociedad desde las particularidades de sus actores sociales y del círculo en el que confluyen las dinámicas de las redes y negociaciones que surgen al interior de ella. Para el caso del "Contrabando", que comúnmente ha sido estudiado bajo la perspectiva de una práctica que va contra el "bando" o edicto, una acción que va en contra de la norma legal del comercio $^{55}$, se debe tener en cuenta que su naturaleza como fenómeno a través del cual se han podido precisar las dinámicas de las redes geográficas y de los actores sociales, lo convirtieron en una práctica sociocultural totalmente común conectada al ejercicio de la política local, que a su vez forjaba la puesta en escena de una lucha por el poder y el dominio de esas redes.

\footnotetext{
${ }^{53}$ AGN, Residencias, 21, fls. $811 \mathrm{v}-812 \mathrm{v}$.

${ }^{54}$ AGN, Residencias, 21, fls. 811v-812v.

${ }^{55}$ Muriel Laurent, "El contrabando en Colombia durante el Siglo XIX (1821-1886): fuentes documentales y aspectos metodológicos para su estudio", América Latina en la Historia Económica, México, Asociación Mexicana de Historiadores Económicos, 2005, pp. 158-159.
} 